\title{
Preliminary results of safety and efficacy of the interleukin 1 receptor antagonist anakinra in patients with severe lupus arthritis
}

\author{
B Ostendorf, C Iking-Konert, K Kurz, G Jung, O Sander, M Schneider
}

Ann Rheum Dis 2005;64:630-633. doi: 10.1136/ard.2004.025858

\begin{abstract}
Background: Joint involvement occurs in most patients with systemic lupus erythematosus (SLE), and severe lupus arthritis is often refractory to conventional treatments. Anakinra is used in the treatment of rheumatoid arthritis, but its therapeutic potential has not been proved in patients with SLE.

Objective: To determine the safety/tolerability and efficacy of anakinra in patients with SLE with leading joint involvement.

Methods: In patients with SLE with active polyarthritis and no other uncontrolled systemic/organ manifestations, $100 \mathrm{mg} /$ day anakinra was self administered subcutaneously for 3 months. Disease activity was assessed by VAS, number of swollen/tender joints, ECLAM score, and serological and immunological measures.

Results: Four patients with SLE were studied; anakinra was safe in all four patients and no drug related serious adverse events occurred. A subjective benefit was seen in all patients and a trend towards better activity measures after 4 weeks. After an initial response, one patient left the study because of an arthritic flare after 6 weeks.

Conclusion: In this study anakinra was apparently safe and well tolerated and led to clinical and serological improvement. Anakinra might be an interesting alternative in individual patients with lupus arthritis not responding to conventional treatments.
\end{abstract}

$\mathrm{J}$ oint involvement occurs in the majority of patients with systemic lupus erythematosus (SLE), ranging from minor arthralgia to treatment refractory deforming arthritis, known as Jaccoud's arthropathy (JA). ${ }^{12}$

In rheumatoid arthritis (RA) one of the most promising therapeutic approaches is treatment targeted at cytokines, specifically the inhibition of tumour necrosis factor $\alpha(\mathrm{TNF} \alpha)$ or interleukin (IL) $1 .^{3}$ Anakinra (Kineret; Amgen Inc, Thousand Oaks, USA) is a recombinant version of the human ILl receptor antagonist blocking the biological activity of ILl and thus reducing arthritis, cartilage destruction, and bone resorption in RA. ${ }^{4}$ It was admitted in America and Europe in 2001/2002 for the treatment of severely active RA. ${ }^{5}$ In addition to its role in inflammatory joint disease, ${ }^{4}$ the claim that ILl might also be involved in the aetiology of glomerulonephritis in $\mathrm{SLE}^{6}$ provided sufficient potential evidence to introduce anakinra to patients with SLE. To date, as far as we know, no data on anakinra treatment in lupus arthritis have been published.

\section{METHODS}

The study was designed as an open, single centre, pilot trial involving patients aged 18-65 years with SLE and severe, treatment refractory polyarthritis/JA ( $\geqslant 6$ swollen joints or $>3$ swollen joints and tendovaginitis in at least two locations and $\geqslant 6$ tender joints) and no other uncontrolled major organ involvement, diagnosed according to the American College of Rheumatology criteria for the classification of SLE. ${ }^{7}$ SLE was otherwise to be controlled by a stable dose of corticosteroids (CORT; $\leqslant 15 \mathrm{mg} /$ day) and/or concomitant antirheumatic/ immunosuppressive drugs (unchanged for 6 months before study entry); treatment of pain with non-steroidal antiinflammatory drugs (NSAIDs) and/or other drugs was to be administered in a stable dose 4 weeks before and throughout the study. Anakinra (100 mg) was self administered subcutaneously daily over the 3 month study period. Safety and efficacy were assessed before the study and after 4 and 12 weeks by clinical (European Consensus Lupus Activity Measurement (ECLAM), ${ }^{8}$ total joint count of swollen and tender joints, visual analogue scale (VAS)) and laboratory measures (for example, anti-dsDNA antibodies (Abs), C3/C4, blood count, $\mathrm{C}$ reactive protein (CRP), and urine analysis).

\section{RESULTS}

Four patients with SLE (two male, two female) with an average age of 38 years (range 32-46) were recruited by the Centre for Rheumatology/University of Duesseldorf. All patients had non-erosive polyarthritis (three patients with deforming JA, one patient with symmetrical finger polyarthritis, all with normal conventional radiography) refractory to previous treatment, including NSAIDs, antimalarial drugs (AM), CORT, methotrexate (MTX), cyclophosphamide (CYC), and azathioprine (AZA). These patients presented no other major organ involvement for at least 6 months before entering the study. Table 1 shows the characteristics of the patients.

\section{Case 1}

A 33 year old man, diagnosed with SLE in March 2000, was initially treated with CORT, AM, and NSAIDs for leading arthritis, with 5-mesalazine for colitis (December 2000), and finally with CYC pulse therapy for lupus nephritis (March 2001-December 2002; WHO type III). Because of treatment refractory and deforming JA he was enrolled in the study in September 2003. At session t4 (see table 2) he responded clinically with a reduction in swollen and painful joints and serologically with a slight decrease in acute phase parameters (CRP) and anti-dsDNA Abs and with an increase in

Abbreviations: Abs, antibodies; $A M$, antimalarial drugs; ANA antinuclear antibodies; AZA, azathioprine; CORT, corticosteroids; CRP, $C$ reactive protein; CYC, cyclophosphamide; ECLAM, European Consensus Lupus Activity Measurement; IL, interleukin; JA, Jaccoud's arthropathy; MTX, methotrexate; NSAIDs, non-steroidal antiinflammatory drugs; RA, rheumatoid arthritis; SLE, systemic lupus erythematosus; TNF, tumour necrosis factor; VAS, visual analogue scale 


\begin{tabular}{|c|c|c|c|c|c|c|}
\hline $\begin{array}{l}\text { Patient } \\
\text { No }\end{array}$ & $\begin{array}{l}\text { Age } \\
\text { (years) }\end{array}$ & Sex & $\begin{array}{l}\text { Concomitant drugs for SLE at } \\
\text { study entry ( }(0)\end{array}$ & $\begin{array}{l}\text { Clinical/organ } \\
\text { manifestations at } \\
\text { study entry (10) }\end{array}$ & ANA titre* & $\begin{array}{l}\text { ENA } \\
\text { profile }\end{array}$ \\
\hline 1 & 33 & $M$ & $\begin{array}{l}\text { Chloroquine } 500 \mathrm{mg} / \text { day } \\
\text { Acetylsalicylic acid } 300 \mathrm{mg} / \text { day } \\
\text { Mesalazine } 2000 \mathrm{mg} / \text { day } \\
\text { Rofecoxib } 25 \mathrm{mg} / \text { day }\end{array}$ & $\begin{array}{l}\text { Arthritis (Jaccoud) } \\
\text { Leucopenia/lymphopenia } \\
\text { Colitis (stable) }\end{array}$ & $1 / 640$ & $\mathrm{Neg}$ \\
\hline 2 & 41 & $F$ & $\begin{array}{l}\text { Chloroquine } 250 \mathrm{mg} / \text { day } \\
\text { Prednisone } 10 \mathrm{mg} / \text { day } \\
\text { Azathioprine } 100 \mathrm{mg} / \text { day } \\
\text { Acetylsalicylic acid } 300 \mathrm{mg} / \text { day } \\
\text { Rofecoxib } 25 \mathrm{mg} / \text { day }\end{array}$ & $\begin{array}{l}\text { Arthritis (Jaccoud) } \\
\text { Malaise }\end{array}$ & $1 / 1280$ & $\mathrm{Neg}$ \\
\hline 3 & 33 & $\mathrm{~F}$ & $\begin{array}{l}\text { Chloroquine } 250 \mathrm{mg} / \text { day } \\
\text { Prednisone } 10 \mathrm{mg} / \text { day } \\
\text { Paracetamol } 500-2000 \mathrm{mg} / \text { day }\end{array}$ & $\begin{array}{l}\text { Arthritis (Jaccoud) } \\
\text { Malaise } \\
\text { Myalgia } \\
\text { Anaemia } \\
\text { Leucopenia }\end{array}$ & $1 / 1280$ & SSA \\
\hline 4 & 45 & $M$ & $\begin{array}{l}\text { Hydroxychloroquine } 400 \mathrm{mg} / \text { day } \\
\text { Prednisone } 15 \mathrm{mg} / \text { day } \\
\text { Rofecoxib } 25 \mathrm{mg} / \text { day }\end{array}$ & $\begin{array}{l}\text { Arthritis } \\
\text { Malaise }\end{array}$ & $1 / 1280$ & $\mathrm{Neg}$ \\
\hline
\end{tabular}

complement C3. The only side effect of anakinra was a local skin reaction at the injection site during the first 2 months. Because of remission of arthritis the drug was discontinued in December 2003. So far, no further relapse has occurred.

\section{Case 2}

A 41 year old woman, with SLE diagnosed in December 1998, was initially treated for arthritis with CORT, NSAIDs, and MTX (since December 1998) then, as she did not respond with AZA and AM, anakinra ( $100 \mathrm{mg} /$ day) was introduced in August 2003 because of persisting polyarthritis. After three injections she developed pneumonia during concomitant treatment with $100 \mathrm{mg} \mathrm{AZA} /$ day; this led to admission to hospital and antibiotic treatment. Because of the initially good clinical response, anakinra was restarted at a reduced dose (100 mg every other day) 4 weeks after recovery from the infection, again with a positive impact on the painful and swollen joints.

The patient is still receiving $100 \mathrm{mg}$ anakinra every other day during the follow up period. No further signs of infection have occurred.

\section{Case 3}

A 33 year old woman, with SLE diagnosed in April 1990, was initially treated for arthritis with AM, CORT, and NSAIDs. Because of progression of joint deformity and functional loss, MTX was added in March 2003. Despite a good response, MTX was discontinued after 2 months because of side effects, resulting in a relapse of arthritis. Therefore the patient was enrolled in the study in July 2003. After 14 injections of anakinra (100 mg/day) there was a clinical response with a reduction in swollen and painful joints and a serological response with a slight reduction in CRP. We noted a mild skin reaction at the injection site (after 1 month, lasting for 2 weeks), myalgia (after the seventh injection, lasting for about 5 months; improved under NSAIDs), and an upper respiratory tract infection in September 2003, treated with oral antibiotics. After 8 months' treatment, she had a renewed arthritic flare and anakinra was discontinued as the disease was insufficiently controlled.

\section{Case 4}

A 45 year old man diagnosed in April 2002 as having SLE with severe polyarthritis initially responded to MTX. Because of lupus pneumonitis, he was switched to intravenous CYC pulse therapy, resulting in an improvement. In November 2002 he developed septic endocarditis, necessitating mitral valve replacement. In January 2003 his arthritis relapsed. As CORT and AM (started in March 2003) failed to control the condition, he was enrolled in our study in July 2003. After 10 injections of anakinra ( $100 \mathrm{mg} /$ day), he responded clinically with a reduction in swollen and painful joints and serologically with a decrease in CRP ( 106 to $4 \mathrm{mg} / \mathrm{l}$ ). No side effects were seen. Nevertheless, after 6 weeks the patient developed active arthritis again and the treatment was discontinued in October 2003 as the disease was insufficiently controlled.

\section{DISCUSSION}

Although $\mathrm{AM}^{9}$ and $\mathrm{MTX}^{10}$ are well studied and commonly used in patients with SLE with joint involvement, the control of lupus arthritis is still a core problem.

Table 2 Anti-dsDNA Abs, complement factors C3/C4, CRP, VAS, number of swollen and tender joints at $t 0,+4$, and $t 12$ (weeks)

\begin{tabular}{|c|c|c|c|c|c|c|c|c|c|c|c|c|c|c|c|c|c|c|}
\hline \multirow[b]{2}{*}{ Patient No } & \multicolumn{3}{|c|}{$\begin{array}{l}\text { anti-dsDNA Abs } \\
(\mathrm{U} / \mathrm{ml}) \dagger\end{array}$} & \multicolumn{3}{|c|}{$\mathrm{C} 3 / \mathrm{C} 4(\mathrm{mg} / \mathrm{ll} \ddagger$} & \multicolumn{3}{|c|}{ CRP $(m g / l) \S$} & \multicolumn{3}{|c|}{ VAS } & \multicolumn{3}{|c|}{$\begin{array}{l}\text { Number of tender } \\
\text { joints }\end{array}$} & \multicolumn{3}{|c|}{$\begin{array}{l}\text { Number of swollen } \\
\text { joints }\end{array}$} \\
\hline & 10 & $\uparrow 4$ & 112 & 10 & †4 & $\uparrow 12$ & 10 & $\uparrow 4$ & 112 & 10 & †4 & 112 & 10 & t4 & $\uparrow 12$ & 10 & 14 & +12 \\
\hline 1 & 124 & 115 & 59 & $800 / 150$ & $1030 / 130$ & $990 / 140$ & 8 & 7 & 6 & 40 & 0 & 20 & 6 & 5 & 5 & 4 & 0 & 0 \\
\hline 2 & 3 & 3 & 3 & $1050 / 220$ & $1000 / 190$ & $1040 / 170$ & 61 & 28 & 14 & 40 & 30 & 30 & 8 & 3 & 3 & 6 & 3 & 3 \\
\hline 3 & 18 & 22 & 13 & $990 / 210$ & $1080 / 190$ & $1060 / 230$ & 41 & 27 & 33 & 50 & 40 & 50 & 7 & 6 & 17 & 8 & 0 & 0 \\
\hline 4 & 130 & 140 & * & $1630 / 180$ & $1480 / 190$ & * & 106 & 4 & * & 80 & 40 & * & 26 & 16 & * & 15 & 3 & * \\
\hline
\end{tabular}

*No 12 week (†12) data available, patient flared after 6 weeks although responding initially; tnormal value $<7 \mathrm{U} / \mathrm{ml}$; †normal value C3 $900-1800 \mathrm{mg} / \mathrm{l} ; \mathrm{C} 4100-400 \mathrm{mg} / \mathrm{l} ;$;normal value $<5 \mathrm{mg} / \mathrm{l}$. 


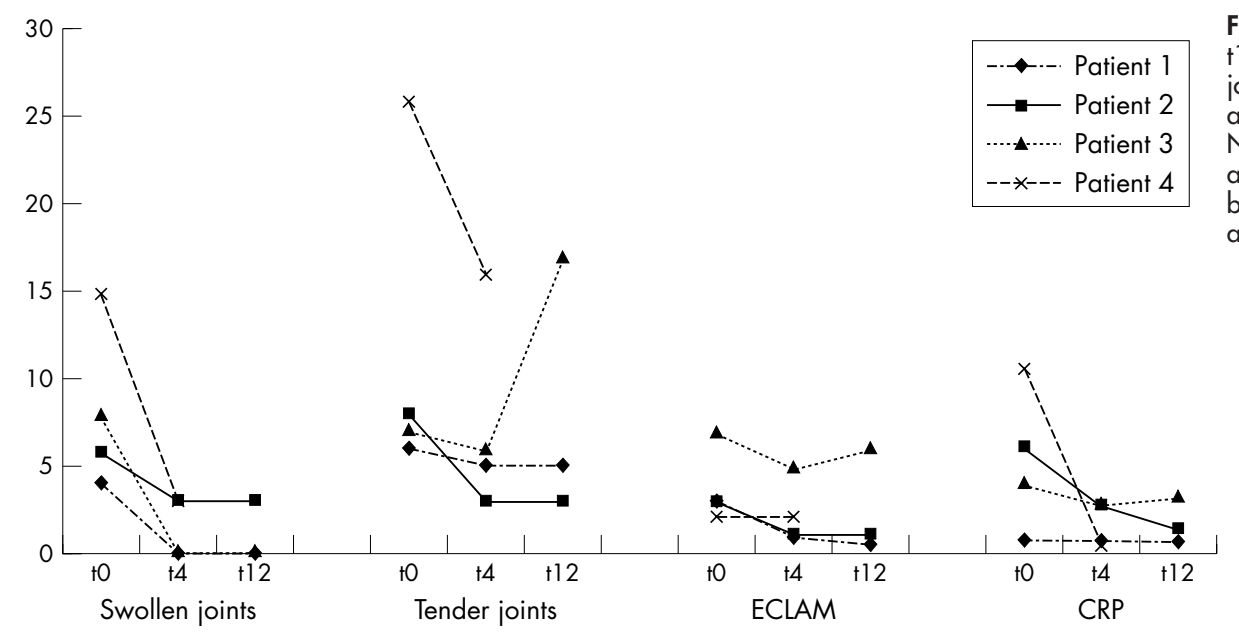

Figure 1 Follow up data $(+0,+4$, and $\dagger 12$ weeks) for the number of swollen joints, number of tender joints, ECLAM and CRP $(\mathrm{mg} / \mathrm{dll})$ for all four patients. Note: no +12 (12 weeks) data were available for patient 4 (drop out because of uncontrolled disease activity).

Despite the fact that patients with RA have now been treated sufficiently for more than 10 years with TNF $\alpha$ blockers, only single reports of patients with connective tissue diseases treated with biological agents have been published. ${ }^{11}$ The observation of newly developed antinuclear antibodies (ANA) and anti-dsDNA Abs, ${ }^{12}$ as well as cases of drug induced lupus ${ }^{13}$ has so far hampered the evaluation of TNF $\alpha$ blocking in connective tissue diseases. ${ }^{11}$ With anakinra a promising new approach in cytokine targeted treatment was recently admitted for the treatment of active RA, ${ }^{5}$ but its use in the treatment of SLE has not yet been described.

This study presents the first administration of anakinra in four patients with treatment refractory lupus arthritis. Although the number of patients is small and their characteristics are heterogeneous, we showed that anakinra is well tolerated and apparently safe and that certain clinical and serological improvements were achieved, bearing in mind that surrogate markers for monitoring treatment responses in SLE are not yet available and validated in detail.

In all four patients enrolled in the study, we found a decrease in the clinical measures tender joint count and $\mathrm{ECLAM}^{8}$ after four weeks (t4); this is similar to comparable RA studies. ${ }^{35}$ After 12 weeks, however, the clinical activity measures tended to increase again (fig 1, table 2). So far our preliminary results do not allow a detailed explanation for that observation. During the follow up period, patient 1 remained in remission after discontinuation of anakinra, patient 3 was still receiving anakinra, and two patients were switched to a different treatment because of lack of efficacy: patient 4 after 6 weeks and patient 3 after 32 weeks. In clinical practice, dropout rates in RA are comparable to those of our study cohort, with $<50 \%$ of patients continuing to receive anakinra after 6 months. ${ }^{5}$ Again parallel to reports from RA studies, we observed a decrease in CRP at t4 in all patients (t0: mean (SD) 54 (40) mg/l; t4: mean (SD) 16.5 (12.7) $\mathrm{mg} / \mathrm{l} ; \mathrm{p}=0.06)$. When raised at t0, anti-dsDNA Abs decreased over the study period (patients 1 and 3 ). Complements $\mathrm{C} 3 / \mathrm{C} 4$ improved slightly in patients 1 and 3, while not altering significantly in the other two (table 2). In contrast with RA, we introduced anakinra as a monotherapy in the standard dosage ( $100 \mathrm{mg}$ subcutaneously/daily), not added to MTX but to concomitant drugs such as AM (in all patients) and to AZA (in patient 2).

The safety of anakinra in patients with RA has been established in large scale trials and studies of long term use ${ }^{14}$; the most commonly reported adverse event in the present study was an injection site reaction in patients 1 and 3 . The occurrence of pneumonia in one of our patients (patient 2) was probably due to the concomitant immunosuppression with AZA. Nevertheless, she was re-exposed because of the good clinical effect and showed no further signs of infection. Throughout the study and the follow up period, there were no signs of SLE flares in other organ systems-for example, skin or kidneys.

Our preliminary results suggest that anakinra might be an interesting therapeutic alternative for individual patients with SLE and active joint involvement or JA not responding to conventional treatment. Efficacy and tolerability were comparable to data achieved in patients with RA. Tender joint count, ECLAM, and CRP may be measures for assessing the therapeutic response in studies of patients with SLE and arthritis (fig 1). Further controlled clinical investigations of the long term effects of ILl blockade, particularly its safety, need to be evaluated in a larger cohort of patients with SLE and polyarthritis.

\section{Authors' affiliations}

B Ostendorf, C Iking-Konert, O Sander, M Schneider, Centre for Rheumatology, Department of Endocrinology, Diabetology and Rheumatology, Heinrich-Heine-University Duesseldorf, 40225 Düsseldorf, Germany

K Kurz, G Jung, Department of Radiology, Heinrich-Heine-University Duesseldorf, 40225 Duesseldorf, Germany

This study was presented as a poster at the Annual European Congress of Rheumatology EULAR 2004 in Berlin, Germany, 9-12 June 2004

Correspondence to: Dr B Ostendorf, ostendorf@med.uni-duesseldorf.de

Accepted 22 August 2004

Published Online First 2 September 2004

\section{REFERENCES}

1 Dubois EL, Tuffanelli DL. Clinical manifestations of systemic lupus erythematosus. JAMA 1964;190:104-11.

2 Ostendorf B, Scherer A, Specker C, Modder U, Schneider M. Jaccoud's arthropathy in systemic lupus erythematosus: differentiation of deforming and erosive patterns by magnetic resonance imaging. Arthritis Rheum 2003;48:157-65.

3 Bresnihan B, Alvaro-Gracia JM, Cobby M, Doherty M, Domljan Z, Emery P, et al. Treatment of rheumatoid arthritis with recombinant human interleukin- 1 receptor antagonist. Arthritis Rheum 1998;41:2196-204.

4 Firestein GS, Boyle DL, Yu C, Paine MM, Whisenand TD, Zvaifler NJ, et al. Synovial interleukin-1 receptor antagonist and interleukin-1 balance in rheumatoid arthritis. Arthritis Rheum 1994;37:644-52.

5 Cohen S, Hurd E, Cush J, Schiff M, Weinblatt ME, Moreland LW, et al. Treatment of rheumatoid arthritis with anakinra a recombinant human interleukin-1 receptor antagonist, in combination with methotrexate. Arthritis Rheum 2002;46:614-24.

6 Sturfelt G, Roux-Lombard P, Wollheim FA, Dayer JM. Low levels of interleukin1 receptor antagonist coincide with kidney involvement in systemic lupus erythematosus. Br J Rheumatol 1997;36:1283-9. 
7 Tan EM, Cohen AS, Freis JF, Masi AT, McShane DJ, Rothfield NF, et al. The 1982 revised criteria for the classification of systemic lupus erythematosus. Arthritis Rheum 1982;25:1271-7.

8 Vitali C, Beneivelli W, Isenberg DA, Smolen JS, Snaith ML, Sciuto M, et al. Disease activity in systemic lupus erythematosus: report of the Consensus Study Group of the European Workshop for Rheumatology Research. II Identification of the variables indicative of disease activity and their use in the development of an activity score. Clin Exp Rheumatol 1992;10:541-7.

9 Nayak V, Esdaile JM. The efficacy of antimalarials in systemic lupus erythematosus. Lupus 1996;(suppl 1):S23-7.

10 Sato El. Methotrexate therapy in systemic lupus erythematosus. Lupus 2001;10:162-4.
11 Manger K, Manger B. TNF alpha-antagonists in collagen vascular disease. Z Rheumatol 2003;62:240-5.

12 Pisetsky DS. Tumor necrosis factor alpha blockers and the induction of antiDNA autoantibodies. Arthritis Rheum 2000;43:2381-2.

13 Mohan AK, Edwards ET, Cote TR, Siegel JN, Braun MM. Drug-induced systemic lupus erythematosus and TNF-alpha blockers. Lancet 2002;360:646.

14 Jiang Y, Genant HK, Watt I, Cobby M, Bresnihan B, Aitchison R, et alD. A multicenter, double-blind, dose-ranging, randomized, placebo-controlled study of recombinant human interleukin-1 receptor antagonist in patients with rheumatoid arthritis: radiologic progression and correlation of Genant and Larsen scores. Arthritis Rheum 2000;43:1001-9. 